\title{
Genealogía de los motines que no fueron. "Tarifazos", resistencia y lazo moral
}

\author{
Genealogy of the riots that were not. "Tarifazos", resistance and \\ moral ties
}

\author{
Federico Juan Bauso Beltrán fedebauso@gmail.com \\ http://orcid.org/0000-0002-1891-4068
}

Universidad de Buenos Aires/Universidad Nacional de las Artes (Argentina)

\section{Resumen}

El artículo repone el contexto de cambio de gobierno nacional en la Argentina de 2015-2016. En este sentido, y a partir de recuperar ciertas características del activismo (militancia) identificado con la gestión saliente (kirchnerista), propone el análisis en torno a los posicionamientos, expectativas y resistencias de estos sectores de cara al gobierno de Cambiemos y su definición de aumentar las tarifas de los servicios públicos conocida como "tarifazo". De esta forma, se construye una genealogía de algo que no fue (los motines) para 
incoporar una reflexión sobre los repertorios de acción, la movilización social y los lazos morales.

Palabras clave: Militancia política; Cambiemos; Kirchnerismo; política argentina.

\section{Abstract}

The article replaces the context of change of national government in Argentina from 2015-16. In this sense, and after recovering certain characteristics of activism (militancy) identified with the outgoing management (Kirchner), it proposes the analysis around the positions, expectations and resistance of these sectors facing the government of Cambiemos and its definition of increasing the rates of public services known as "tarifazo". In this way, a genealogy of something that was not (the riots) is built to incorporate a reflection on the repertoires of action, social mobilization and moral ties.

Keywords: Political militancy; Let's change; Kirchnerism; Argentine politics.

La conducción sin espíritu creador no existe, y es permanente creación porque todos los casos que la historia plantea en la conducción son distintos, como distintos son los factores que intervienen en cada caso Juan Perón, 1974

Cernimos, a modo de punto de apertura y proyección, los meses electorales (sobre todo, desde octubre) y el cambio de gobierno que se da en la Argentina en 2015. Entendemos que, si bien múltiples, algunas tendencias socioculturales y políticas que venían delimitándose en el tiempo anterior, cobraron cuerpo. En este sentido, ese momento, es de cierre, de conclusión del período peronista-kirchnerista; la "década ganada" (1) y su oleada. Recuperamos el concepto de "oleadas" acuñado por el vicepresidente de Bolivia, Álvaro García Linera, porque frente a una conceptualización de los ciclos históricos que se presentan como ley natural, reivindicamos: 
la lógica de los flujos, las oleadas, que es un poco la experiencia que uno adquiere en la vida. Las transformaciones se dan por oleadas. La gente se articula, se unifica, crea sentido común, tiene ideas fuerza, se convierte en ser universal, es decir, ser que pelea por todos. Logra derechos, acuerdos, Estado, política. Pero luego pasa a la vida cotidiana. No puede estar en asamblea todos los días. Tienes que ir a ver qué va a pasar con tu hijo, con el crédito de la casa. Viene el reflujo. Pero luego, más pronto que tarde, puede venir otro flujo (2016).

El después será un devenir tramado por un nuevo régimen neoliberal, de derechas democráticas -dirán algunxs, por el mero hecho de su acceso al gobierno vía urnas-; con sus narrativas y héroes pero, también, con sus exclusiones, destierros y aprisionamientos. Así, el triunfo electoral de la alianza Cambiemos (2), en general, y de Mauricio Macri, en particular; hace síntesis con el momento de reflujo de los gobiernos populares en el contexto regional bastardeados por la espectacularización mediática de los casos de corrupción política (lo moral) y las retracciones de las economías locales (lo económico) en una nueva etapa del capitalismo internacional.

En este sentido, en la fase actual de la hegemonía del capital, este modelo sustenta el pasaje del yuppie de Wall Street en los ochenta al emprendedorismo de Silicon Valley, y la siliconización del mundo (Sadin, 2018), como paradigma del éxito contemporáneo. De Gordon Gekko, personaje encarnado por Michael Douglas en la película de Oliver Stone, a Steve Jobs, Bill Gates o, más acá, Marcos Galperin, CEO de Mercado Libre; el self-made que, a partir de una idea, funda una corporación. En este sentido, la primacía del management, el coaching y el ludismo en el ámbito laboral (Han, 2014), como valores propios de este nuevo liberalismo digital (Sadin, 2018). Un nuevo individualismo que busca la producción del individuo en sí: un individuo responsable de sí mismo y activo con el fin de evitar o minimizar eventuales costos a la sociedad. En este sentido, como señala Denis Merklen:

Una vez que el individuo ha sido definido como el único responsable de su propia situación, cuando toda regla social es vista como un límite a la libertad individual y la atención política se torna hacia el sujeto individual, ya nadie piensa en la construcción de colectivos capaces de proteger a los individuos ni se busca regular la vida social en función de algún ideal sobre la buena vida, de una concepción colectiva sobre el mejor modo de vivir juntos (2013: 85-86).

En ese contexto, donde se trastocó lo público y lo privado, el eje moral, valorativo y laboral; el entramado de organizaciones "nacionales y populares" que, hasta ese momento, se entendían 
parte del dispositivo de articulación entre el Estado y los sectores bajos, que se disponía como universo de expresiones y trayectorias que hacía síntesis en el kirchnerismo como identidad política; y que se veía alumbrado bajo la palabra, fraseo y línea de la ex presidenta Cristina Fernández de Kirchner (CFK); se encontró presto a "resistir" sin más herramienta que el "lo que diga la Jefa" (3). Una resistencia que evocó tanto a la épica peronista como a la canción "Resistiré" de Estela Raval, en un movimiento que mezcló las clases (entendida como el proceso activo una relación históricamente emplazada) y los consumos. Como reseña el grupo kirchnerista, simbólico de ese tiempo, Resistiendo con Aguante (4) en una nota de prensa de 2016:

Hoy un artículo especula sobre el término 'Resistiendo', y lo toman como algo negativo. Quizás para comprender mejor ese sentir del $48.60 \%$ de la población baste con oír el clásico 'Resistiré' de Estela Raval, ya que el nombre inocentemente proviene de allí (si tienen dudas al menos lo podrían preguntar a alguna de las 500.000 personas que participan, ningún medio se comunicó con ninguna)... y el agregado 'con aguante' es más nostálgico que revolucionario, "soy como el junco que se dobla pero siempre sigue en pie... soportaré los golpes y aunque los sueños se rompan, resistiré".

Dimos cuenta de un contexto de cambio de gobierno y de signo ideológico. También, relevamos cómo funcionó la intervención activista en el periodo que se cerraba, qué mecánicas comenzaron a dejar de operar y cuáles variables mutaron. Nos interesa, ahora, recuperar algunas líneas que anteceden al momento sobre el que pivoteamos para el análisis (elecciones y cambio de gobierno) ya que nos sirve para construir la proyección y su fundamento.

Precuela: "el candidato es el Proyecto" (5)

Aquel día posterior al balotaje presidencial de noviembre de 2015, entre los segmentos afines al gobierno que salía, había una sensación de que lo que se perdía era vasto, la tangencia de la conciencia histórica del último tiempo, el macro relato de lo Nacional y Popular.

El sentir era de orfandad: Mauricio Macri había venido a matar al pater familias, el Estado; y a sepultar un periodo que había dado lugar a una ola democratizadora heredera del "espasmo participativo" de 2001 (Rinsesi, 2016). El triunfo de la alianza Cambiemos (no solo para la presidencia sino en la gobernación de la provincia de Buenos Aires) terminó con el periodo de 
gobierno popular comenzado en 2003 por Néstor Kirchner y continuado por su esposa, Cristina Fernández de Kirchner. Gestiones que fortalecieron un Estado que intercedió en favor de los intereses de los sectores populares. Una oleada de ampliación de derechos o de democracia ampliada (Rinesi, 2016) que levantó la bandera de los derechos humanos y la integración regional; y que dinamizó el consumo de los sectores medios y bajos y la movilidad social ascendente. Proceso autodenominado "década ganada" en el que los gobiernos kirchneristas ponderaron el rol de la política para la resolución de los conflictos y la administración de las voluntades. En este sentido, la sociedad toda, directa o indirectamente, se politizó. Se recuperaron el debate público y las pasiones antagonistas (kirchnerismo/antikirchnerismo, la "grieta") (6) amplificadas por la potencia de las nuevas tecnologías en contexto post industrial de las sociedades capitalistas.

A su vez, y como huella (y patrón futuro) en el camino a la derrota del partido de gobierno, nos interesa rememorar la campaña de su Frente para la Victoria (FPV) (7). En aquel momento, La Cámpora (8), Nuevo Encuentro, Peronismo Militante, Partido Comunista Congreso Extraordinario y otras agrupaciones políticas integrantes de lo que alguna vez fuera el espacio de "Unidos y Organizados" (9) -inserto en el FPV- pasaron de criticar, primero, a esconder, después, al candidato presidencial propio Daniel Scioli, dando lugar a una campaña con un perfil "no sólo confuso, sino contradictorio" (Grimson, 2015). Como señala Gabriel Vommaro:

Los mismos que habían designado a Daniel Scioli como candidato se ocuparon de volver a dejar claro durante casi toda la campaña que no era el candidato kirchnerista que hubiesen querido. 'El candidato es el proyecto', decían, pero al mismo tiempo pedían a sus votantes que lo apoyaran. Todo en pos de ese bien colectivo que administraban los dirigentes. En definitiva, pedían a sus votantes que no votaran por el candidato que los líderes habían designado, sino por la candidata que no podía postularse. $Y$ además exigían movilizarse, estar atentos para defender lo conquistado (2016).

A su vez, entre las generales de octubre y el balotaje de noviembre en el que el FPV se medía con Macri y Cambiemos, las organizaciones reaccionaron impulsadas por la participación ciudadana y el activismo no orgánico (del que Resistiendo con Aguante era una expresión destacada) que reimpulsó la figura de Scioli de cara a la instancia definitoria:

Una movilización social desorganizada, aunque de gran magnitud, decidió en las últimas semanas salir de la encerrona y aceptar lo que el candidato tenía para decirles. A veces seguía 
sin nombrarlo. 'Macri no', se decía. La propuesta era modesta, la razón se dirigía al pasado (Vommaro, 2016).

En este sentido, ante la derrota y la desorientación posterior, las agrupaciones tendieron a asentar sus principales rasgos, límites y anclajes, en sintonía con estos sectores conmovidos y conmocionados por el triunfo macrista asimilando a quienes no se "volvieron a sus casas" (sobretodo, franjas etareas de la juventud y la tercera edad de extracción media). Así, refutar notas del diario Clarín, sacarse una fotografía con un cartel "bancando" a CFK o coordinar una volanteada se transformaron en las formas participativas de una militancia que mixturaba redes sociales con organización partidaria. Estratos que, en su espontaneísmo inicial y su estructuración posterior, entramaron su agenda en función de lo que construían los periodistas y medios afines al kirchnerismo (C5N, Victor Hugo, Roberto Navarro, etcétera) y la figura indiscutida de CFK. Así, las organizaciones contagiaron y se contagiaron, en un movimiento de ida y vuelta permanente, de los repertorios de acción de esos sectores. Recuperamos, en este sentido, la concepción de repertorio acuñada por Charles Tilly quien afirma que:

En su acepción media, la idea de repertorio presenta un modelo en el que la experiencia acumulada de los actores se entrecruza con las estrategias de las autoridades, dando como resultado un conjunto de medios de acción limitados, más práctico, más atractivo y más frecuente que muchos otros medios que podrían, en principio, servir los mismos intereses (1984: 99).

A su vez, las orgánicas auguraron y esperaron a una ex Presidenta dirigente de la oposición toda.

En la coyuntura analizada, Clerici, Cruz y Goyburu (2016) detallan que la alianza Cambiemos privilegió una campaña que articulaba redes sociales (por parte del PRO) con la estructura territorial tradicional de la Unión Cívica Radical (UCR) y, de esta forma, desarrolló de manera pareja ambos espacios. Según indican los autores, el FPV evidenció más dificultades a la hora de aggionarse y encarar las tareas de una campaña 2.0. En este sentido, se plantea que "fue generalizada la ausencia digital de los principales dirigentes del espacio" (p. 15). En relación, César Gazzo Huck (2016), consultor en nuevas tecnologías y jefe de la campaña digital \#Sciolipresidente, da cuenta cómo la cultura organizacional del Partido Justicialista (PJ) epicentro del FPV-, "más anclada en lo territorial que en 'lo digital', hizo que las plataformas web fueran en muchos casos dejadas de lado o utilizadas como último recurso; redes como 
creaciones ad hoc para apoyar acciones que estaban sucediendo en otros espacios". Gazzo Huk afirma que a veces lo llamaban "para que saliera a pintar paredes. Pero cuando viajamos en tren, no miramos el paredón con pintadas: miramos el celular".

Proyección: "se viene el estallido" (10)

Pero "la Jefa" no habló. O, mejor, después de la derrota y como conductora y tiempista política, marcó el horizonte estratégico: construir una nueva mayoría. Firmamento último que, en términos gramscianos, remite a la construcción de un nuevo bloque histórico, la "unidad de los contrarios y de los distintos" (Gramsci, 2003). Eso había dicho el 9 de abril, frente a los tribunales de Comodoro Py, en el contexto de una citación a indagatoria por un caso de corrupción reconvertido en acto de masas del "vamos a volver" kirchnerista. $\mathrm{Y}$, entonces, los flyers, las charlas y los posteos se embanderaron con edificación de una "nueva mayoría". Sí ¿pero cómo?

Faltaba táctica. Ese fenómeno que, antes, durante los gobiernos populares, se resolvía en función de la articulación territorial y frentista (11) vía política pública había sido clausurado. Es decir, a cada frente o sector a abordar por la estructura militante le correspondía un abanico de programas sociales y definiciones de gobierno para "militar". De esta forma, se garantizaba que el Estado llegara a cada "beneficiario" por medio del entramado militante. Denis Merklen (2013) marcará que, en el contexto contemporáneo, en el marco de las políticas de individuación quien ya no es titular de un derecho se convierte en "simple beneficiario". De esta forma, la persona en cualquier momento puede verse privada de la ayuda si no cumple con lo que se le exige en nombre de la contrapartida.

La forma y operación por medio de la cual se vehiculizaba materialmente este proceso variaba según el espacio: mesas partidarias en esquinas barriales concurridas, recolección de firmas y beneficiarios en planillas y listados, charlas temáticas o proyecciones de películas; un entramado de herramientas para llevar adelante la "bajada" (12). El ejemplo más destacado de este compuesto fueron las llamadas "interministeriales" que se realizaban en los territorios y funcionaban a modo de evento con la participación efectiva de los agentes de programas ministeriales articulados con la militancia local a modo de feria itinerante. Así, se acordaba un día en el que en alguna plaza o barriada se hacían presentes integradores de Anses, abogados de los Centros de Acceso a la Justicia del Ministerio de Justicia y Derecho Humanos, operadores del RENAPER (13) del Ministerio del Interior o promotores del Ministerio de Salud. Al no ser más partido en ejercicio de gobierno, todo lo antedicho quedaba en el recuerdo. El entramado militante construido en base a la articulación con el Estado caía en desuso bajo la 
sazón trágica del cierre de los programas y la cancelación de políticas públicas de la gestión de Cambiemos. $Y$ entonces, en el marco de la desorientación post derrota electoral, cierta praxis militante del espacio kirchnerista tendió a repetirse en loop como cáscara vacía e intentando una reflexión autocrítica y analítica que no era fomentada desde las jerarquías orgánicas que no encontraban en CFK ninguna palabra públicamente ordenadora. Se había perdido, pero no se asumían las carencias propias; no había línea política pero se condenaba la que se intentaba por fuera del modelo canónico; no había espacios de discusión pero se reprimía cualquier toma de posición.

Además, sobre el núcleo descripto que daba sentido y norte a la práctica militante, que evitaba discusiones de línea y formas de intervención, y, sobretodo, después del triunfo por el 54\% de los votos del FPV en 2011; comenzó a erigirse una narrativa épica militante que ninguneó a la política como forma de construir y negociar mayorías (deseo programático posterior) expulsando sectores más que integrando. Como indica Gabriel Vommaro:

La victoria electoral en las presidenciales de 2011 (...) fue interpretada de manera rápida y forzada por buena parte del kirchnerismo: parecía que, en consonancia con una antigua creencia peronista, erosionada en 1983, se había constituido una mayoría, por así decirlo, natural. De esta manera, reconocía su liderazgo y su interpretación en la voz del líder y de su tropa, y ya no era presa de la fragilidad de los vínculos políticos que deben confirmarse y reforzarse de manera recurrente. Dos años después, la derrota en las legislativas de 2013 y la aparición del Frente Renovador fueron tomadas con cierto desdén. Exageración, en un momento; minimización, en el otro (2016).

Así, operó un movimiento pernicioso para un espacio que se asume popular y se pretende hegemónico que podemos sintetizar en una proporción inversa: a más política había menos discurso y relato heroico; a menos política, más. De la Ley de Servicios de Comunicación Audiovisual ("ley de medios"), la Asignación Universal por Hijo (AUH) o la nacionalización de los Yacimientos Petrolíferos Fiscales (YPF) a la gesta por la Fragata Sarmiento y la puja antiimperialista contra los "fondos buitres". De la realidad efectiva a la narración hiperideologizada. La épica del aumento del sachet de leche en el marco de un "populismo de minorías" que "condujo al alejamiento, por vía del hartazgo indolente o el rechazo enfurecido, de sectores sociales que antes lo habían acompañado (al kirchnerismo)" (Natanson, 2018).

Entonces, durante el verano de 2016, CFK no daba cuenta de qué hacer, sus apariciones habían sido esporádicas, en el Calafate; muchxs referentes orgánicos no sentaban posición ni 
daban respuestas a sus bases. A su vez, la cotidianeidad se tornaba aún más sórdida dada la persecución de la nueva gestión a los militantes insertos en la estructura estatal. En aquel momento, se evidenció que aquello que se planteaba inicialmente como "irreversible" (14), no lo era.

Como gesto sin cuerpo, tras la derrota, los agrupamientos que nutrían el espacio "Unidos y Organizados" colapsaron y mutaron. Expulsaron y se fragmentaron en el intento de sostener viejas prácticas para un nuevo contexto. El "lo que diga Cristina" se había tornado en muletilla vacía que daba cuenta de la carencia de línea política y mirada táctica para intervenir en la realidad, acumular en diferentes frentes, articular sectores y aportar a la construcción de una alternativa opositora. Así, el primer atisbo "resistente" remitió al repertorio de prácticas aprehendidas: la mesa, la planilla y el flyer. En este marco, con el comienzo de la gestión de gobierno de la alianza Cambiemos, y frente al aumento de las tarifas de luz, agua, gas, nafta, etcétera; militar el rechazo a los "tarifazos" se tornaba camino para la revuelta. De esta forma, se extendieron las multisectoriales contra los aumentos, los "cacerolazos" en las esquinas barriales y los volantes denunciando los aumentos. Frente a cada subida, ante cada dicho del ministerio de Energía macrista y ex CEO de Shell, Juan José Aranguren, un nuevo diciembre se hacía inminente. Las imágenes y comentarios que aludían al helicóptero (en referencia a la huida en diciembre de 2001 del ex presidente Fernando De la Rúa) pululaban con tono socarrón.

Con el tiempo, se hizo manifiesto que esa "olla a presión" que componía el ajuste y la degradación de las condiciones de vida de los sectores populares y medios locales, y que se construía como metáfora para leer la realidad desde el kirchnerismo (medios, organizaciones y referentes); no "volaba por los aires". Aún más, en 2017, el candidato de la alianza de gobierno en provincia de Buenos Aires, Esteban Bullrich, derrotó en elecciones legislativas a CFK. Bullrich proveniente del partido del ex ministro de economía delarruista Ricardo López Murphy, Recrear, era de las figuras más endebles para lanzar a la campaña en provincia de Buenos Aires. Blanco, alto, de los barrios nortes y heráldica patricia evidenciaba el estereotipo de Cambiemos deseado por el kirchnerismo. Y, a pesar de esto, el sustrato inmaterial del peronismo, el ethos descamisado y conurbano lo había elegido en detrimento de "la Jefa" ¿qué pasaba? A su vez, las grandes movilizaciones contra las tarifas, las puebladas, no aparecían y "la gente" se resignaba a pagar, naturalizando, trágicamente, la precariedad y la lógica del aumento permanentemente. Vidas en inflación que buscaban astucias para pagar. 


\section{"Tarifazos"}

Las tarifas y los subsidios públicos a los servicios se convirtieron en tema de agenda ya desde la campaña electoral de 2015, cuando, desde el macrismo, se construyó un consenso sobre la necesidad de activar una modificación retrayendo la intervención del Estado en función del déficit fiscal heredado. En este sentido, como señalan Martín Schorr y Francisco Cantamutto (2017), “Cambiemos lo tomó como uno de sus ejes de intervención ya que lo consideraba expresivo de las 'distorsiones' de la economía kirchnerista”.

Los gobiernos de Néstor y Cristina Kirchner concibieron a los servicios públicos como recursos estratégicos. De esta forma, el retraso en las tarifas cumplía diversos roles. Por una parte, darles cierta legitimidad entre segmentos sociales que se beneficiaban y, por la otra, subsidiar parcialmente los costos industriales. Pero, esta definición generó precios que fueron cada vez más altos, por las transferencias económicas a las empresas prestatarias. De esta forma:

El peso de este rubro en las cuentas públicas terminó por ser casi equivalente al déficit fiscal. Y fue tomado por Cambiemos como argumento para atacar el problema a partir de una concepción de neto corte mercantilista. Así, se insistió con la vieja idea de que se trataba de una 'mentira' que había que 'sincerar'. Supuestamente, solo abriendo espacio a que los precios fluctuaran libremente se darían las señales correctas para estimular la actividad y la inversión, suposición ya rebatida bajo la Convertibilidad (Schorr y Cantamutto, 2017).

Tras el triunfo electoral, Cambiemos impulsó -como había planteado en campaña- un aumento de las tarifas que provocó malestar social y presentación de reclamos judiciales de parte de los damnificados. Sobre este fenómeno, y con las prácticas y concepciones descriptas, se montó la militancia de las organizaciones reivindicadas kirchneristas. Con las carencias relevadas, y sobre todo, ante el silencio de CFK; los "tarifazos" delimitaron un norte activista al cual seguir, reduciendo "las reciprocidades humanas al nexo salarial", constriñéndolas al vínculo económico (Thompson, 1995: 293).

En un primer momento, el eje militante abordó la vulneración del gobierno de los mecanismos de consulta establecidos en la ley, con epicentro en las audiencias públicas. Luego, el núcleo discursivo denunció lo drástico de los aumentos tarifarios. Así, otra vez, las mesas barriales y las planillas retomaron sus esquinas en colectas de firmas cuyo fin último era el contacto con el damnificado con cierto tono, de parte de la militancia, de "se lo dijimos" (en referencia a la 
campaña de denuncia de las medidas que tomaría el macrismo si ganaba realizada por el kirchnerismo en 2015; renominada por Cambiemos como "Campaña Bu!").

Planillas, "ruidazos" en los barrios, multisectoriales contra los tarifazos; las agrupaciones políticas del kirchnerismo intentaron organizar el malestar con el repertorio de prácticas que le era propio. Pero la cosa, no explotaba, el "estallido" no venía; las instancias se iban diluyendo y la agenda del gobierno y los medios afines avanzaba contribuyendo a naturalizar el "sinceramiento" de la economía y de los precios, a cerrar la canilla del "despilfarro" de subsidios kirchnerista. En este sentido, entendemos con Stuart Hall que:

hay una lucha continua y necesariamente irregular y desigual, por parte de la cultura dominante, cuyo propósito es desorganizar y reorganizar constantemente la cultura popular; encerrar y confinar sus definiciones y formas dentro de una gama más completa de formas dominantes. Hay puntos de resistencia, hay también momento de inhibición. Ésta es la dialéctica de la lucha cultural. En nuestro tiempo, esta lucha se libra continuamente, en las complejas líneas de resistencia y aceptación, rechazo y capitulación, que hacen de la cultura una especia de campo de batalla constante. Un campo de batalla donde no se obtienen victorias definitivas, pero donde siempre hay posiciones estratégicas que se conquistan y se pierden (1984: 5).

De esta forma, el cambio cultural kirchnerista no se materializó como "irreversible" sino del orden de la disputa, la "década gánada" podía pujarse, en términos de sentido, como "década robada" y el conceso en torno a la quita de los subsidios a los servicios públicos podían vislumbrarse como sacrificio necesario en el marco de un discurso del ascetismo, como dirá Gonzalo Assusa, ordenador empresarial. Así:

Consumir menos, gastar poco, trabajar mucho y demandar nada, forma menos parte de una política energética, productiva y económica que de una pura estética del ascetismo que tiene resonancia comunicativa en sensibilidades políticas hoy reavivadas. (...) El ascetismo macrista es un ascetismo de la estética, consonante con la idolatría del emprendedurismo al estilo Steve Jobs, con la sobriedad como gesto indistinguiblemente moral y económico que se porta hasta en la vestimenta, la basura y las llaves de luz (2018).

Un modelo que se contrapone con la promoción del consumo durante los gobiernos kirchneristas como motor de la economía -que se "calentaba" vía demanda- y que les granjeó, 
tanto a Cristina como a Néstor, fuerte legitimidad entre los estratos medios y bajos. Como releva G. Assusa:

Entre 2004 y 2013, por ejemplo, se multiplicó por seis el patentamiento de automotores; la proporción de hogares propietarios de teléfonos celulares aumentó casi un 50 por ciento; la cantidad de argentinos que viajó al exterior por vacaciones aumentó más del 60 por ciento; las ventas en supermercados y grandes centros comerciales creció a un ritmo del 10 al 15 por ciento interanual, y todo esto sin contar la aparición de las grandes ferias populares al estilo de La Salada (2018).

Con el triunfo de la alianza Cambiemos el proceso anterior es leído en términos de exceso en todos los órdenes: una economía inflacionaria regida por el exceso de emisión, un gobierno (y una Presidenta) desbordada por exceso de politización y corrupción, una sociedad y una cultura del despilfarro por exceso de consumo y populismo (15). Como dirá el economista radical y titular del Banco Nación durante la gestión cambiemista, Javier González Fraga (2016), los gobiernos kirchneristas "le hicieron creer a un empleado medio que podía comprarse celulares e irse al exterior". Esa discursividad sería la que estabilizaría y naturalizaría el pregón macrista como sentido común. Es decir, como "la concepción del mundo absorbida acríticamente de los varios ambientes culturales en medio de los cuales se desarrolla la individualidad moral del hombre medio" (Gramsci, 1971). Y, por eso, en aquel momento, las argucias populares se dirigieron más a cómo hacer para pagar o reducir el consumo que a cómo resistir en términos de lucha política. Como reseña Mónica Yemayel:

Distintas personas que cumplen funciones tanto en Edenor como en Edesur dejaron trascender que cuando un cliente que no puede pagar se acerca a la empresa, se estudia caso por caso para determinar -de acuerdo al historial del cliente y su situación financiera actual- si es plausible un plan de financiación o si la única salida es pagar o quedarse sin luz (2018).

La austeridad empresarial se impone al desborde populista y el modelo ascetista a la orgía dionisiaca; así, el "sinceramiento" de las tarifas se constituye en la resaca inminente luego de más de una década de fiesta. 


\section{Lazo moral}

Edward Palmer Thompson examina, en su libro Costumbres en común (1995), los motines de subsistencia en la Inglaterra del siglo XVIII. En este sentido, plantea como un déficit de los análisis preexistentes no considerar al pueblo como agente histórico con anterioridad a la Revolución Francesa:

Antes de este período la chusma se introduce, de manera ocasional y espasmódica, en la trama histórica, en épocas de disturbios sociales repentinos. Estas irrupciones son compulsivas, más que autoconscientes o autoactivadas, son simples respuestas a estímulos económicos. Es suficiente mencionar una mala cosecha o una disminución del comercio, para que todas las exigencias de una explicación histórica queden satisfechas (1995: 213).

El autor, además de darle entidad histórica al sujeto popular, repone un tejido de variables morales y legitimadoras que colman el lazo económico y dan cuenta del fenómeno. Así:

El motín de subsistencia en la Inglaterra del siglo XVIII fue una forma muy compleja de acción popular directa, disciplinada y con claros objetivos. (...) Esto estaba a su vez basado en una visión tradicional consecuente de las normas y obligaciones sociales, de las funciones económicas propias de los distintos sectores dentro de la comunidad que, tomadas en conjunto, puede decirse que constituyen la economía moral de los pobres. Un atropello a estos supuestos morales, tanto como la privación en sí, constituían la ocasión habitual para la acción directa. (Thompson, 1995: 216-217).

Para decirlo de manera simplificada, había una economía moral que activaba o desactivaba la medida de acción directa en función que los sectores populares se vieran, en términos actuales, zarpados o no en relación con el precio del alimento (pan). Thompson dirá que es un "modelo de protesta social que se deriva de un consenso con respecto a la economía moral del bienestar público en tiempos de escasez" (p. 279).

De la misma forma, y más acá, Gabriel Vommaro y Julieta Quirós (2011) repiensan el "clientelismo" a partir de la etnografía. Lo clientelar alude a "la asociación entre la politicidad barrial y la circulación de recursos de asistencia social" (p. 65) y los autores, al igual que Thompson, recuperan la dimensión moral de estas transacciones a priori económicas ya que "como en cualquier relación social, esas negociaciones involucran ciertas nociones de lo justo y 
lo injusto, y (...) esta dimensión moral, lejos de constituir una máscara del cálculo, es precisamente aquello de lo que el cálculo se trata" (p. 83). Así incorporan la noción "cálculo moral" para repensar estas prácticas en las que:

Los bienes materiales -el qué del intercambio- son, junto con otros gestos, parte de los índices de esta consideración por el otro y su propio valor que se define en relación con esta dimensión. La magnitud moral -valor- de lo que se intercambia, el cómo -que dosis de interés y compromiso, bien individual y bien común-, y la posibilidad de contar con el otro son, de este modo, algunos de los elementos principales de lo que podríamos llamar cálculo moral (p. 79).

\section{Conclusiones: lo moral como catalizador social}

Como la encrucijada de los caminos que venimos delimitando, entendemos, en relación con los "tarifazos" y el estallido social que auguraba la militancia kirchnerista a partir de la intervención en la realidad con un repertorio de prácticas propias de otro contexto histórico; que hay algo del lazo moral construido por el macrismo con la sociedad (con anterioridad a su triunfo) que operó catalizando en dos dimensiones. Por un lado, en torno a la autodefinición del espacio político de Cambiemos con los valores del ascetismo y la austeridad -y un sinfín de cadenas siginificantes relativas-; por el otro, en contraste con el gobierno del que inicialmente era oposición y luego suplantó. En este sentido, junto con el entramado mediático que le fue afín, edificaron al kichnerismo como sinónimo de despilfarro, populismo y corrupción. Así, como consecuencia de este proceso, el lazo moral del gobierno con la sociedad, en los albores de la gestión Cambiemos, soportó, planteado como sacrificio (16), los aumentos en las tarifas de los servicios y confirmó, dos años después, el rumbo elegido a través de las urnas. Pero, también, es el resquebrajamiento de ese vínculo, además de la degradación económica, lo que propugno de manera transversal, popular y masiva las movilizaciones en rechazo de la reforma previsional (17) impulsada por el gobierno nacional y que atentaba directamente contra la figura vulnerable de "Ixs abuelxs". Será en ese contexto en el que Jorge Bergoglio, el Papa Francisco, lanzará un spot en el que dirá que "un pueblo que no cuida a los abuelos y no los trata bien es un pueblo que no tiene futuro" (18) y la opinión pública, trasgrediendo los núcleos duros, verá con ojos críticos la medida. Entonces, si bien en términos económicos el gobierno de Macri encaró reformas que degradaron la cotidianeidad de la mayoría de las y los argentinos; el lazo moral en torno a lo sacrificial operó en relación al aumento de las tarifas y se desactivó cuando 
fueron vulnerados consensos sociales más amplios -y transgrieta- que la articulación macrista coyuntural. Las y los jubilados, el endeudamiento con el Fondo Monterio Internacional (FMI) o la desaparición forzada de Santiago Maldonado (19) pusieron en la palestra lo inmoral del contrato neoliberal.

Notas

(1) Título adoptado por el gobierno de CFK para hacer referencia a la década que va de 2003 a 2013.

(2) Alianza integrada, a nivel nacional, por: Unión Cívica Radical, Partido Demócrata Progresista, Partido Conservador Popular, Coalición Cívica-Afirmación para una República Igualitaria (ARI), Propuesta Republicana (PRO), Partido Fe, Partido del Diálogo.

(3) "Jefa" es la denominación utilizada por la militancia kirchnerista para referirse a CFK y que apela a remarcar su función de liderazgo único del espacio político.

(4) Resistiendo con aguante (RCA) es un grupo "secreto" de Facebook creado el 26 de octubre de 2015 -día posterior de las generales presidenciales- a partir de la iniciativa de Tita Ayan en San Martín de los Andes (Neuquén). El colectivo tuvo una intensa actividad en el período que va desde su creación hasta los primeros meses del gobierno de Cambiemos, reuniendo adherentes al kirchnerismo que no estaban encuadrados en organizaciones preexistentes. En una segunda etapa, RCA se territorializa en diferentes agrupamientos locales de todo el país sin una coordinación centralizada y con el anclaje que les brindaba el grupo de Facebook.

(5) Eje de campaña del espacio Unidos y Organizados en 2015 de cara a las elecciones presidenciales.

(6)Término acuñado por el periodista del grupo Clarín, Jorge Lanata, para definir la divisoria entre kirchneristas y antikirchneristas.

(7) Frente integrado, a nivel nacional, por: Partido Justicialista, Partido Intransigente, Partido Federal, Partido Comunista, Partido Solidario, Encuentro por la Democracia y la Equidad, Partido Humanista, Partido Frente Grande, Partido de la Victoria, Kolina, Partido de la Concertación Forja, Frente H.A.C.E.R por el Progreso Social, Partido por la Soberanía Popular (Jujuy).

(8) La Cámpora (LC) es una organización política peronista/kirchnerista fundada en 2006, fruto del encuentro de organizaciones preexistentes (Juventud Presente, GEN, etcétera) y la iniciativa de Néstor Kirchner. Si bien en un inicio se la consideró una agrupación de la juventud 
peronista, a posterior, y con el ingreso de múltiples referentes/militantes; trascendió este recorte. Su principal referente es Máximo Kirchner, hijo de Néstor y Cristina. A su vez, muchos de los militantes/ex funcionarios más reconocidos de la gestión de CFK son parte de la organización: Eduardo "Wado" De Pedro, Andrés "Cuervo" Larroque, Mariano Recalde, Juan Cabandié, y otros.

(9) Unidos y Organizados fue un frente de agrupaciones kirchneristas lanzado por CFK en un acto en el estadio del club Vélez Sarsfield en 2012.

(10) "Se viene" es una canción popularizada por el grupo de rock Bersuit Vergarabat a fines de la década del noventa y que muchos consideran, junto con la cumbia villera, la banda de sonido de la crisis del 2001.

(11) Retomamos la concepción leninista de frente de masas en los que interviene el partido de cuadros a través de su militancia. De esta forma, estudiantil, sindical, tercera edad, género; pueden ser espacios en los que se intenta vehiculizar la línea política táctica para cada sector en el marco de una concepción estratégica de despliegue.

(12) Término que refiere a llevar, transmitir a las bases políticas las interpretaciones de mensajes de CFK.

(13) Registro Nacional de las Personas (RENAPER)

(14) Consigna utilizada por La Cámpora durante 2014.

(15) Entendido, desde la perspectiva liberal, como la conjunción de los valores negativos asociados al intervencionismo estatal, el asistencialismo y la concentración de poder. De la Venezuela de Chávez a la Argentina de los Kirchner.

(16) En este sentido, el ministro de Modernización, Andrés Ibarra (2018) planteará que "La gente se va a dar cuenta de que hay un camino de sacrificio, que para mucha gente es una cagada, que le significa un esfuerzo tremendo, pero no hay ninguna duda de que es el camino de salida".

(17) El diario El País de España hablará de "Batalla campal en Buenos Aires para frenar la reforma de las pensiones".

(18) Recuperado de http://www.lapoliticaonline.com/nota/109912-en-medio-de-la-reformajubilatoria-el-papa-pidio-cuidar-a-los-ancianos/

(19) Santiago Maldonado desapareció el 1 de agosto de 2017, tras la represión de Gendarmería Nacional en la Lof en Resistencia de Cushamen, Chubut. Estuvo desaparecido 78 días. Su cuerpo sin vida fue encontrado el 17 de octubre de 2017 en el Río Chubut, 400 metros río arriba de donde fue visto por última vez. 


\section{Bibliografía}

Assusa, G. (2018). Pará de consumir. Revista Anfibia. Recuperado de http://www.revistaanfibia.com/ensayo/para-consumir/

Castelucci, O. (director) (1974). Perón. Conducción política. Buenos Aires: Biblioteca del Congreso de la Nación.

Clerici, P.; Cruz, F. y Goyburu, L. (2016). Dos territorios. Las elecciones argentinas 2015 en Twitter. Recuperado de https://www.coalicionesgicp.com.ar/wpcontent/uploads/2016/12/Clerici-Cruz-y-Goyburu-2017.pdf

García Linera, A. (2016). Derrotas y victorias. Recuperado de http://vicepresidencia.gob.bo/Derrotas-y-victorias

Granovsky, M. (2016). "Las transformaciones son por oleadas", entrevista a Álvaro García Linera, Telesur. Recuperado de https://bit.ly/2IXO06S

Gramsci, A. (1971). El materialismo histórico y la filosofía de Benedetto Croce. Buenos Aires: Nueva Visión.

Gramsci, A. (2003). Notas sobre Maquiavelo, sobre la política y sobre el Estado moderno. Buenos Aires: Nueva Visión.

Grimson, A. (2015). El peligro de subestimar. Revista Anfibia. Recuperado de http://www.revistaanfibia.com/ensayo/el-peligro-de-subestimar/

Cué, C. (19/12/2017). Batalla campal en Buenos Aires para frenar la reforma de las pensiones. El País. Recuperado de https://bit.ly/2CC2XOZ

Hall, S. (1984). Notas sobre la deconstrucción de lo popular. En Samuels, R. (ed.). Historia popular y teoría socialista. Barcelona: Crítica.

Han, B. (2014). Psicopolítica. Neoliberalismo y nuevas técnicas de poder. Buenos Aires: Herder.

Merklen, D. (2013). Las dinámicas contemporáneas de la individuación. En Castel, R.; Kessler, G.; Murard, N. y Merklen, D. Individuación, precariedad, inseguridad. ¿Desintitucionalización del presente? Buenos Aires: Paidós.

Natanson, J. (2018). ¿Por qué? Buenos Aires: Siglo XXI Editores.

Rinesi, E. (2016). En Latinoamérica los verdaderos republicanos somos nosotros: los populistas. En García Linera, A.; Sader, E. y Rinesi, E. Restauración conservadora y las nuevas resistencias en Latinoamérica. Buenos Aires: Fundación Germán Abdala. 
Sadin, E. (2018). La siliconización del mundo. Buenos Aires: Caja Negra Editores.

Schorr, M. y Cantamutto, F. (2017). Tarifazo: del derecho a la mercancía. Revista Anfibia. Recuperado de http://www.revistaanfibia.com/ensayo/tarifazo-derecho-mercancia/

Thompson, E. P. (1995). Costumbres en común. Barcelona: Crítica.

Tilly, C. (1984). Les origines du répertoire de l'action collective contemporaine en France et en Grande-Bretagne. Paris: Revue d'Histoire.

Vommaro, G. y Quiróz, J. (2011). “Usted vino por su propia decisión”: Repensar el clientelismo en clave etnográfica. Revista Desacatos, 36, pp. 65-84.

Vommaro, G. (2016). El candidato no es el proyecto. Revista Anfibia. Recuperado de http://www.revistaanfibia.com/ensayo/el-candidato-no-es-el-proyecto/

Yemayel, M. (2018). Todo lo que dejaste de hacer para pagar las tarifas. Revista Anfibia. Recuperado de http://www.revistaanfibia.com/cronica/lo-dejaste-pagar-las-tarifas/

\section{Notas periodísticas}

Bastión Digital (8/04/2016). La campaña en las redes. Recuperado de http://ar.bastiondigital.com/notas/la-campana-en-las-redes

Diario Jornada (16/07/2018). El ministro Ibarra habla de "un camino del sacrificio, que es el correcto. Recuperado de https://bit.ly/2IZuZB7

Infobae (27/05/2016). González Fraga: "Le hicieron creer a un empleado medio que podía comprarse celulares e irse al exterior". Recuperado de https://bit.ly/2wqITxB

La Política Online (4/12/2017). En medio de la reforma jubilatoria, el Papa pidió cuidar a los ancianos. Recuperado de https://bit.ly/2IZuQO5

Página/12 (8/03/2015). El candidato es el proyecto. Recuperado de https://www.pagina12.com.ar/diario/elpais/1-267654-2015-03-08.html 